\title{
Pediatrik kalça sorunlarında görüntüleme yöntemleri
}

\author{
Imaging methods in pediatric hip problems
}

\author{
Serhan Ünlü, Mehmet Faruk Çatma, Yenel Gürkan Bilgetekin \\ Dışkapı Yıldırım Beyazıt Eğitim ve Araştırma Hastanesi, Ortopedi ve Travmatoloji Kliniği, Ankara
}

\begin{abstract}
Çocuklarda kalça problemlerini değerlendirmek için anamnez ve fizik muayeneden sonra görüntüleme yöntemlerine sıkça ihtiyaç duyulmaktadır. Gelişen teknoloji ile birlikte tanıya ulaşmak çok kolay olmaktadır. Bunun yanında konvansiyonel radyografi ve ultrasonografinin pediatrik ortopedide kullanımı halen önemini korumaktadır. Konvansiyonel radyografide en çok kullanılan standart antero-posterior pelvis grafisidir. Diğer pozisyonlarda çekilen pelvis grafisinin doğru şekilde uygulanması gerekmektedir. Gereksiz yere grafi çekilmesinin önüne geçilmiş olunur. Ultrasonografi pediatrik kalçada en çok kullanılan bir diğer yöntemdir. Bu yöntem de kolay uygulanır, girişim gerektirmez fakat deneyim gerektirir. Özellikle gelişimsel kalça displazisi tanısını koymada ve tedavi takibinde sıklıkla kullanılmaktadır. Artrografi ise genelde gelişimsel kalça displazisi ameliyatlarında konsantrik redüksiyonun kontrolünde veya manyetik rezonans ile birlikte kullanılarak labrum patolojilerini saptamada tercih edilir. Bilgisayarlı tomografi travmada pelvik yapıların incelenmesinde, ileri dönemde hastalıkların komplikasyonlarını takip etmede ve gelişimsel kalça displazisinde kapalı redüksiyonun kontrolünde kullanılır. Manyetik rezonans görüntüleme kalça eklem içi patolojilerde ve femur başı avasküler nekrozu tanısını koymada oldukça yararlıdır. Sintigrafi ise bu bölgede görülen tümör, osteomiyelit ve stres kırıklarını saptamada yardımcıdır. Bu derlemede pediatrik kalça sorunlarında kullanılan görüntüleme yöntemleri özetlenmiştir.
\end{abstract}

Anahtar sözcükler: kalça; pediatri; radyoloji
Imaging techniques, following history taking and physical examination are often needed to evaluate hip problems of children. Thanks to improved technology it has become a simple task to achieve right diagnosis. However use of conventional radiography and ultrasonography still plays an important role for pediatric orthopaedics. Most frequently used conventional radiography is standard antero-posterior pelvis radiography. Pelvis radiography taken in other positions need to be accurately applied to prevent unnecessary radiographic exposure. Ultrasonography is the other technique mostly used for pediatric hip. This technique is applied with ease as well, requires no intervention, and yet demands experience. This method is largely employed especially for the diagnosis of developmental hip dysplasia and for the follow-up after the treatment. As for arthrography it is generally preferred to control the concentric reduction during the operation of developmental hip dysplasia or, accompanied by magnetic resonance imaging, to determine labrum pathologies. Computed tomography is administered to study pelvic structures for the trauma cases, to keep track of long-term complications of the illnesses and to check closed reduction applied for developmental hip dysplasia. Magnetic resonance imaging is quite helpful to detect pathologies within the hip joint and to diagnose avascular necrosis of the femoral head. Scintigraphy assists to discover tumors, osteomyelitis and stress fractures seen in this area. In this review, a summary of imaging methods used for pediatric hip problems is presented.

Key words: hip; pediatrics; radiology ediatrik kalça sorunları yaş grubuna göre değişiklik gösterir. Yenidoğan döneminde daha çok gelişimsel kalça displazisi görülürken, yaş ilerledikçe septik artrit, Legg-Calvé-Perthes hastalığı, femur başı epifiz kayması, kırıklar ve yürüme döneminin diğer daha az görülen hastalıkları görülmektedir. İyi bir anamnez ve dikkatli yapılan fizik muayene sonrasında istenilen görüntüleme yöntemi, tanıyı daha hızlı koymamızı sağlar ve gereksiz yere tetkik istemekten kurtarır. Ayrıca hastalığın cerrahi tedavisi sonrası takibinde görüntüleme yöntemleri sıkça kullanılmaktadır. Bu derlemede, pediatrik kalça sorunlarında kullanılan görüntüleme yöntemleri özetlenmeye çalışılmıştır.

- İletişim adresi: Op. Dr. Serhan Ünlü, İrfan Baştuğ Cad. Dışkapı Yıldırım Beyazıt Eğitim ve Araştırma Hastanesi, Ortopedi ve Travmatoloji Kliniği, Altındağ, Ankara Tel: 0532 - 4035002 e-posta: serhanunlu@yahoo.com

- Geliş tarihi: 3 Eylül $2014 \quad$ Kabul tarihi: 3 Eylül 2014 


\section{RADYOGRAFi}

Konvansiyonel radyografi pediatrik kalça sorunlarını değerlendirmede en önemli tanı yöntemlerinden birisidir. Kolay uygulanabilir ve ucuz olması avantajlarıdır. Günümüzde dijital tekniklerin gelişmesi ile grafilerin üzerinde değişiklik yapılabilir ve görüntüler saklanabilir hale gelmiştir.

\section{A) Antero-posterior (AP) pelvis grafisi}

Kalça eklemini değerlendirmede en çok kullanılan grafidir. Hasta röntgen masasında supin pozisyonda yatarken kalça $15^{\circ}$ iç rotasyonda olacak şekilde çekilmelidir. Bunu sağlamak için bacaklar ekstansiyondayken patellanın santralde durması sağlanır veya her iki ayak başparmağı birbirine değdirilir. Işın simfizis pubisin ortasından $5 \mathrm{~cm}$ yukarısına gönderilir.

AP pelvis grafisinin ideal olup olmadığını saptamak için kullanılan parametreler (Şekil 1): ${ }^{[1]}$

1) Pelvik rotasyon katsayısı: Horizontal planda pelvisin pozisyonunu belirler. Her iki obturator foramenlerin genişliklerinin oranıdır. Rotasyon yoksa değeri 1'dir; 0,56-1,8 arası değerler kabul edilebilir. ${ }^{[2]}$

2) Simfizis iskiyum açısı: Sagittal planda pelvisin pozisyonunu belirler. Her iki iskiyumun en üst noktası ile simfizisin üst noktasını birleştiren çizgiler arasında kalan açıdır. Açı azaldıkça pelvik eğim azaldı̆̆ı, arttıkça da pelvik eğimin arttığı bildirilmiştir. Tablo 1 'de normal değerleri gösterilmiştir. ${ }^{[3]}$

3) Pelvik tilt indeksi: Obturator foramenin yüksekliğinin Hilgenreiner çizgisi ile simfizis pubis arası mesafeye oranıdır. Pelvis normal pozisyonda bu değer $0,75-1,2$ arasındadır. ${ }^{[4]}$

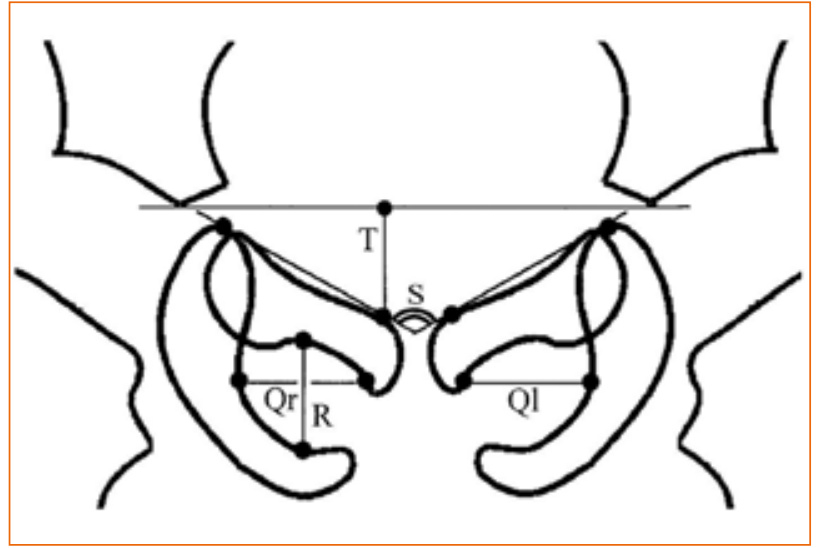

Şekil 1. Pelvis radyografisinde pelvik rotasyonun değerlendirilmesi (Qr/QI), simfizis iskiyum açısı (S), pelvik tilt indeksi $(R / T){ }^{[1]}$
AP radyografide kullanılan referans çizgileri (Şekil 2):

1) Hilgenreiner çizgisi: Her iki Y kıkırdağından geçen horizontal çizgidir.

2) Ombrédanne çizgisi (Perkins): Asetabulumun en dış noktasından Hilgenreiner çizgisine çizilen dik çizgidir. Kalça eklemini dört kadrana böler. Normalde femur başının merkezi alt iç kadranda bulunur.

3) Shenton-Mènard hattı: Normalde femur boynunun mediyal kenarının devamında obturator foramenin üst kenarı vardır. Disloke kalçalarda bu devamlılık bozulmuştur.

4) Klein çizgisi: Femur boynunun üst tarafından teğet geçecek şekilde çizilen çizgidir. Normal kalçada çizgi femur proksimal epifizinin içinden geçer. Femur başı epifiz kaymasında bu çizgi epifızin dışından geçer. ${ }^{[5]}$

AP radyografide ölçülen parametreler (Şekil 3): ${ }^{[1]}$

1) Asetabular indeks: Asetabular çatının değerlendirilmesinde kullanılır. iliumun Y kıkırdağındaki en alt noktası ile asetabulumun en dış noktasından geçen çizgi ile Hilgenreiner çizgisi arasında kalan açıdır. ${ }^{6]}$ Tönnis, hastanın yaşına, cinsiyetine ve tarafına göre normal değerleri belirlemiştir. Ayrica ortalamadan 2 standart sapmaya kadar olanlara hafif displazi, 2 standart sapmadan fazla olanlara ağır displazi olarak tanımlamıştır. ${ }^{[3]}$ Yaşa ve cinsiyete göre normal değerler Tablo 2'de verilmiştir.

2) Yamamuro-A mesafesi: Proksimal femoral metafizin orta noktası ile Hilgenreiner çizgisi arasındaki mesafedir. ${ }^{[7]} 1$ ay -4 yaş arası normal değeri 7-14 milimetredir.

Tablo 1. Simfizis iskiyum açısı değerleri

\begin{tabular}{lc}
\hline Yaş & Sifizis iskiyum açısı \\
\hline $1-2$ ay & $98-130$ \\
$3-4$ ay & $100-135$ \\
$5-6$ ay & $98-128$ \\
$7-12$ ay & $96-126$ \\
$1-2$ yaş & $90-128$ \\
$2-3$ yaş & $90-124$ \\
$3-5$ yaş & $85-115$
\end{tabular}




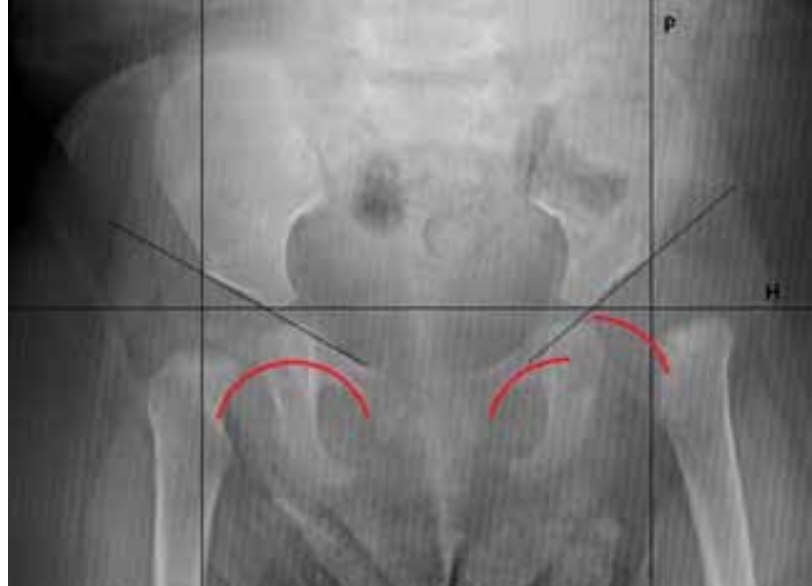

Şekil 2. AP radyografide referans çizgileri. Hilgenreiner çizgisi, Perkins çizgisi, Shenton-Mènard hattı.

3) Yamamuro-B mesafesi: Proksimal femoral metafizin orta noktası ile iskiyumun lateral kenarı arası mesafedir. ${ }^{[7]} 1$ ay -4 yaş arası normal değeri 5-12 milimetredir.

4) Hilgenreiner-H mesafesi: Proksimal femoral metafizin en yüksek noktası ile Hilgenreiner çizgisi arası mesafedir. ${ }^{[6]}$ Normal değeri 8-10 milimetredir.

5) Hilgenreiner-D mesafesi: Proksimal femoral metafizin en yüksek noktasının Hilgenreiner çizgisindeki izdüşümünün, iliumun en alt noktasına olan mesafesidir. ${ }^{[6]}$ Normal değeri 14-16 milimetredir.

6) Smith'in superior deplasmanı ( $h / b$ oranı): Hilgenreiner- $\mathrm{H}$ mesafesinin, sakrumun ortasından geçen hatla Perkins hattı arasında kalan mesafeye oranıdır. ${ }^{[8]}$ Normal değeri $2-5$ yaş arasında 0,10-0,20'dir.

7) Smith'in laterale deplasmanı (c/b oranı): Sakrumun ortasından geçen hattın proksimal femoral metafizin mediyal gagasına uzaklığının Perkins hattına olan uzaklığına oranıdır. ${ }^{[8]}$ Normal değeri 2-5 yaş arasında 0,60-0,85'tir.

8) ACM açısı: Asetabulumun en dış noktası ile (A) en alt noktasını (B) birleştiren çizginin orta noktasından (M) çizilen dik çizginin asetabuluma ulaştığı noktanın (C) belirlenmesinden sonra AC-CM çizgileri arasında kalan açıdır. ${ }^{[3]}$ Asetabulumun derinliği hakkında bilgi verir. Bu açı $45^{\circ}$ olduğunda asetabulum için tam bir yarımküre denebilir; $53^{\circ}$ 'nin üzerindeki değerler ise patolojik olarak kabul edilir (Şekil 4). ${ }^{3]}$

9) Merkez kenar (CE) açısı: Femur başı merkezini asetabulumun en dış noktasına birleştiren çizgi ile femur başı merkezinden dik çizilen çizgi arasındaki

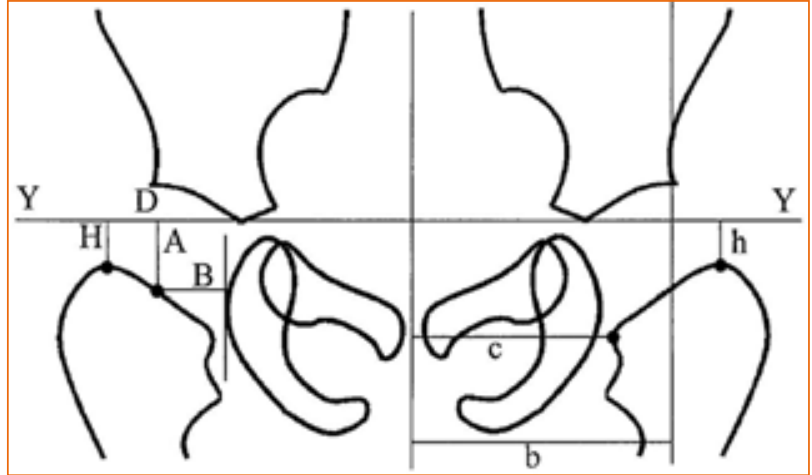

Şekil 3. Pelvis radyografisinde ölçülen parametreler: ${ }^{[1]}$ Y, Hilgenreiner çizgisi; A, Yamamuro-A; B, Yamamuro-B; $H$, Hilgenreiner- $H$ mesafesi; $D$, Hilgenreiner-D mesafesi; $h / b$, Smith'in superior deplasman oranı; c/b, Smith'in lateral deplasman oranı.

Tablo 2. Normal asetabular indeks değerleri

\begin{tabular}{lcc}
\hline Yaş & $\mathrm{K} \mathbf{}$ & Erkek \\
\hline Yenidoğan & $28.8 \pm 4.8$ & $26.4 \pm 4.4$ \\
$<3$ ay & $25 \pm 3.5$ & $22 \pm 4$ \\
$3-6$ ay & $23.2 \pm 4$ & $20.3 \pm 3.7$ \\
1 yaş & $21.2 \pm 3.8$ & $19.8 \pm 3.6$ \\
$1-2$ yaş & $18 \pm 4$ & $19 \pm 3.6$
\end{tabular}

açı ölçülür. ${ }^{[9]}$ Normal değerleri Tablo 3'te verilmiştir (Şekil 4).

10) $M Z$ mesafesi: ACM açısında tarif edilen $M$ noktası ile femur başı merkezi $(Z)$ arasındaki mesafedir. ${ }^{[3]}$ 5-8 yaş arası 5 milimetreden az olmalı, 9-12 yaş arası 4 milimetreden az olmalıdır. ACM açısı $45^{\circ}$ olan kalçalarda her iki nokta aynıdır. Displastik kalçalarda iki nokta arası mesafe artar (Şekil 4).

11) Baş-boyun-diyafiz açısı: Femur boynu ile femur uzun ekseni arasındaki açıdır. İki yaş civarında erkeklerde $137,1^{\circ}$, kızlarda $135^{\circ}$ olup, yavaşça azalarak erişkin dönemdeki $127-130^{\circ}$ değerine ulaşır. ${ }^{[3]}$

Gözyaşı damlası görüntüsü mediyalde pübik kol duvarından, lateralde asetabulumdan, inferiorda ise asetabuler çentikten oluşur. Normalde 6-24 ay arasında belirir. Gözyaşı damlası ile femur başı arası mesafe ölçülmeli ve diğer tarafla kontrol edilmelidir. Eğer bir artış varsa, bu kalçada effüzyon varlığından söz edilebilir. 


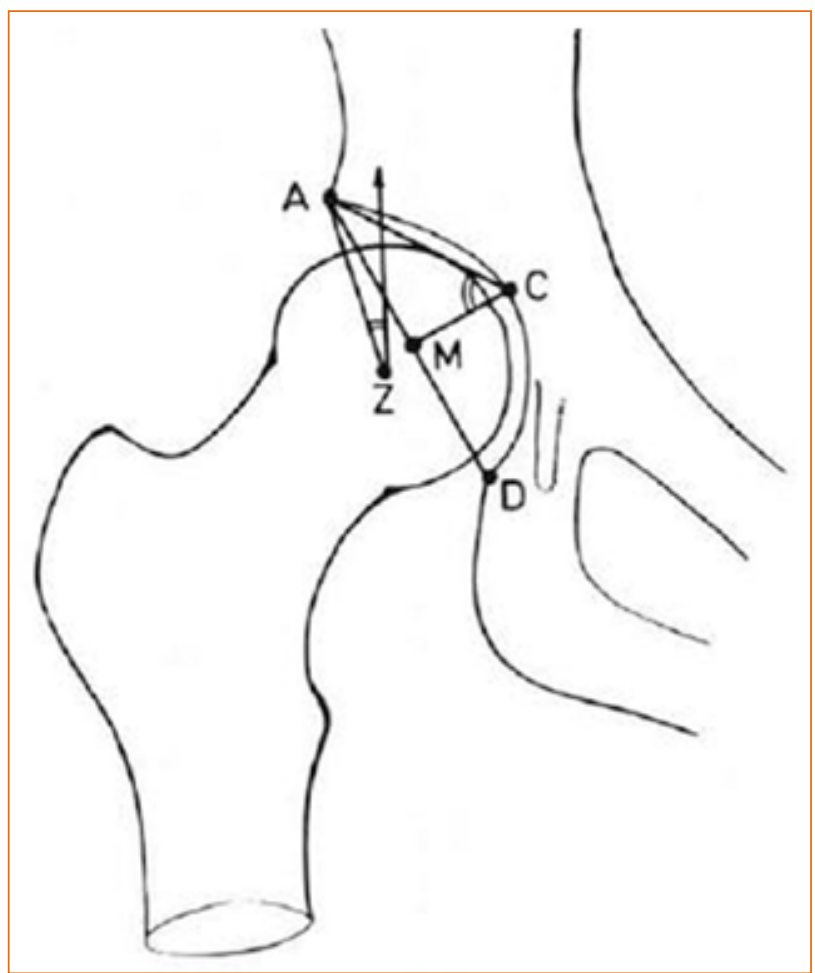

Şekil 4. ACM açısı, CE açısı, MZ mesafesi. ${ }^{[3]}$

Tablo 3. Normal merkez kenar (CE) açısı değerleri

\begin{tabular}{lc}
\hline Yaş & CE açısı \\
\hline $5-8$ yaş & $19^{\circ}$ \\
$9-12$ yaş & $25^{\circ}$ \\
$13-20$ yaş & $26^{\circ}-30^{\circ}$
\end{tabular}

B) Kurbağa pozisyonda lateral pelvis grafisi (Lauenstein)

Hasta supin pozisyonunda yatırılır. Kalça $45^{\circ}$ fleksiyon ve $45^{\circ}$ abduksiyondadır. Özellikle Perthes hastalığında ve femur başı epifiz kaymasında epifizi değerlendirmede yararlıdır.

\section{C) Von Rosen/Andren pelvis grafisi}

Hastanın her iki kalçası $45^{\circ}$ abduksiyonda ve maksimum iç rotasyonda çekilen radyografidir.

\section{D) Dunn/Rippstein grafisi}

Hasta supin pozisyonda yatarken her iki kalça ve dizler $90^{\circ}$ fleksiyonda ve kalçalar $20^{\circ}$ abduksiyondadır. $\mathrm{Bu}$ grafi kalçaların anteversiyonunu değerlendirmede kullanılır (Şekil 5). ${ }^{[10]}$

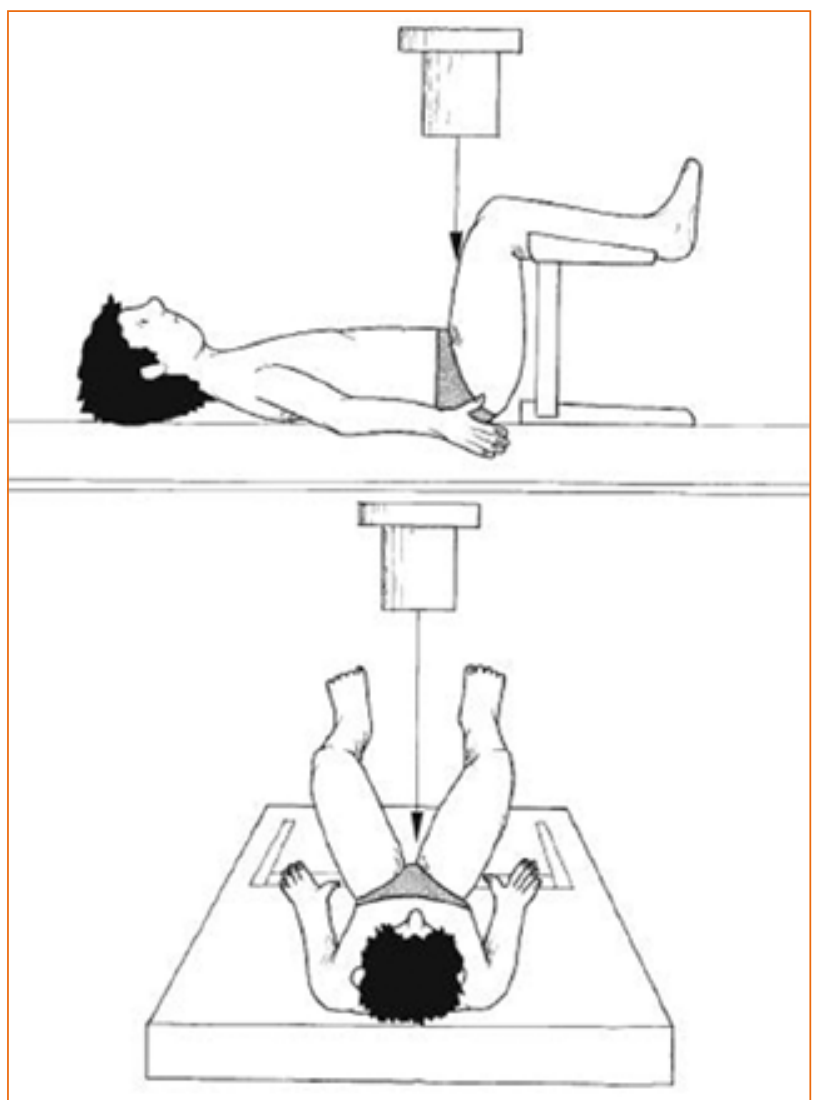

Şekil 5. Dunn-Rippstein grafisi için hastanın pozisyonu. ${ }^{[10]}$

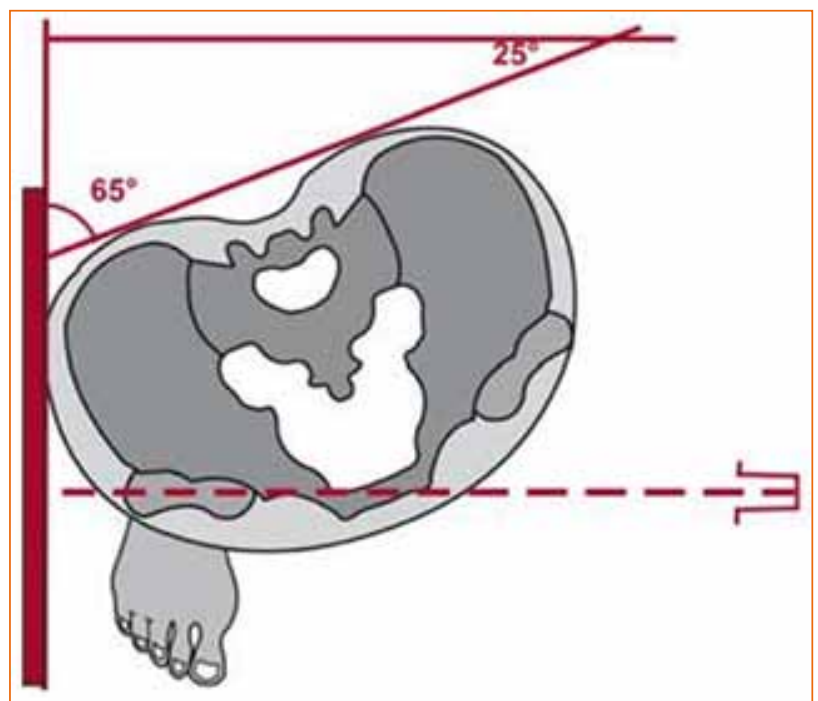

Şekil 6. Ayakta oblik grafi (false profile veya Lequesne). ${ }^{[10]}$

\section{E) Ayakta oblik grafi (false profile veya Lequesne)}

Hasta ayakta dururken kaset ile $65^{\circ}$ açı yapar. Etkilenmiş tarafta ayak film kasetine paralel olarak durur (Şekil 6). ${ }^{[10,11]}$ 


\section{ULTRASONOGRAFI}

Girişim gerektirmeyen yöntem olan ultrasonografi (US) ses dalgalarının vücuttaki dokularla olan etkileşimine dayanır. Yenidoğan döneminde kalçanın büyük bir kısmı kıkırdak yapıdan oluştuğu için standart radyografilere göre US daha çok bilgi vermektedir. En çok yaşamın ilk altı ayında, gelişimsel kalça displazisinin tanısını koymakta kullanılır. Bu amaç için yüksek frekanslı prob (6-10 MHz) gerekir. Kalça US'nin avantajları, çabuk uygulanabilir olması ve çocuk için zararlı olmamasıdır; radyasyon ve sedasyon gerektirmez. Dezavantajları ise deneyim gerektirmesidir. Ileri yaşlarda femur başı epifizinin kemikleşmesinden sonra kullanımı sınırlanmaktadır.

Kalçada hyalen kıkırdak az eko verirken, kapsül orta düzeyde, labrum ve osteokondral bileşke ise güçlü eko verir. Kalçada effüzyon varlığında kabarık olan kapsül altında hipoekoik göllenme görülür. Effüzyon, septik artrit, geçici sinovit, travma veya Perthes gibi birçok hastalıkta görülebilir.

\section{ARTROGRAFi}

Kalça artrografisi invaziv bir işlem olması nedeniyle genel anestezi altındayken uygulanmalıdır. Skopi altında steril şartlarda adduktor longusun altından girilmelidir. Genelde kontrast farmakolojik ajanlar (lopamiro) kullanılır. Chan ve arkadaşları, yaptıkları çalışmada karbondioksit gaz artrografisini kullanmışlar ve ameliyattan sonraki dönemde komplikasyonla karşılaşmadıklarını belirtmişlerdir. ${ }^{[12]}$ Femur başının durumunu ve asetabulumla olan ilişkisini çok iyi gösterir. İşlem sonrasında nötral ve kurbağa pozisyonda grafi alınmalıdır. Günümüzde labrum patolojilerini değerlendirmek için daha çok artro-MR tercih edilmektedir. Perthes hastalığında, femur başının şekline ve labrumun pozisyonuna göre yapılan Laredo sınıflaması kullanılır. ${ }^{[13]}$ Abduksiyonda takılma varsa yararlı bir tanı yöntemidir. Geliş̧imsel kalça displazisi ameliyatından sonra redüksiyonun değerlendirilmesi için kullanılır. Ameliyat sırasında artrografik evreleme için Tönnis sınıflaması şöyledir: ${ }^{[2]}$ Evre l'de femur başı tam olarak yerine oturmuştur. Evre II'de femur başı asetabulum altındadır fakat kapsül, labrum ve transvers asetabuler bağdaki gerginlikten dolayı lateraldedir. Evre III'te femur başı asetabulum dışındadır.

\section{BILGISAYARLI TOMOGRAFI (BT)}

Özellikle multitravma hastalarında pelvisi değerlendirmek için kullanılır. Üç boyutlu rekonstrüksiyon BT ile pelvis ve asetabulumu daha hızlı incelemek mümkündür. Özellikle ameliyat öncesi planlamada yararlıdır. Ayrıca Perthes hastalığında ileri dönemde görülen komplikasyonları belirlemede yardımcıdır. Gelişimsel kalça displazisinde kapalı redüksiyon ve alçılama sonrasında redüksiyonun değerlendirilmesi amacıyla kullanılır. Aksiyel ve koronal kesitlerde asetabulumun durumu, femur başı ile olan ilişkisi, implant kullanıldıysa eklem içine olan uzanımı tespit edilir. Daha ileri yaştaki çocuklarda gelişimsel kalça displazisi mevcutsa, ameliyat öncesinde asetabular ve femoral versiyonu saptamak için kullanılır. Periasetabular osteotomi planlanıyorsa, asetabulum displazisi açısından BT ile değerlendirilir.

\section{MANYETIK REZONANS GÖRÜNTÜLEME (MR)}

MR görüntüleme kalça eklemi ve bu bölgedeki yumuşak dokuları değerlendirmek için kullanılır. Özellikle travma sonrası radyografi ile tespit edilemeyen kırıklarda, eklem içi serbest cisim varlığında ve femur başı avasküler nekrozunda ameliyat öncesi ve sonrasını karşılaştırmada önemlidir. MR görüntü alınabilmesi için hastanın hareketsiz durması gerekmektedir. Bu nedenle, çekim sırasında sedasyon veya genel anestezi uygulamak gerekebilir. Radyografilere göre pahalı olması dezavantajıdır.

Femur başı epifiz kaymasında, eğer radyografide bulgu yok ama klinik şüphe varsa, MR endikedir. MR'de fizis etrafında ödem, eklemde effüzyon olması, erken dönem -pre-slip- olarak değerlendirilir. Futami ve arkadaşları, fizis merkezinde veya posteromediyal bölgede genişleme olabileceğini göstermişlerdir. ${ }^{[14]}$

Son zamanlarda, dokudaki su moleküllerinin hareketinden kaynaklı görüntüler ile bilgi veren diffüzyon MR kullanılır olmuştur. Baunin ve arkadaşlarının yaptığı çalışmada, Pertes hastalığının erken döneminde çekilen diffüzyon MR ile hesaplanan, görünen diffüzyon katsayısı (Apparent Diffusion Coefficient, ADC) hastalığın erken dönemde tanınmasına olanak sağlamıştır. ${ }^{[15]}$

Sebag ve arkadaşları tarafından tanımlanmış olan Dynamic Gadolinium Subtraction (DGS) MR ile epifizyel iskemi erken dönemde tespit edilebilir. ${ }^{16]}$

Kashiwagi ve arkadaşları, gelişimsel kalça displazisinde tedavi öncesinde MR ile asetabulumu değerlendirerek Pavlik tedavisinin başarı oranlarını tespit etmişlerdir. Asetabulumu keskin olanlarda Pavlik tedavisinin başarısı artarken, yuvarlak veya inverte olanlarda başarısızlık görülmüştür. ${ }^{[17]}$

\section{SINTIGRAFi}

Sintigrafi intravasküler olarak verilen radyonüklid maddenin kemikteki dağılımını gösterir. Yüksek oranda duyarlıdır fakat özgün değildir. Tümör, travma ve 
enfeksiyon varlığında tutulum gösterir. Teknesyum (Tc-99m-MDP) en çok tercih edilen radyonükliddir. Bazı olgularda indium-111 kullanılmaktadır. Stres kırıklarda sınırlı ama çok "sıcak" tutulum vardır. Osteomiyelitte yaygın, düzensiz dağılım gösterir. LeggCalvé-Perthes hastalığının erken döneminde etkili bir yöntemdir. Conway tarafından tanımlanmış, Perthes hastalığının revaskülarizasyonu/rekanalizasyonu ile ilgili bir sintigrafik sınıflama vardır. ${ }^{[18]}$ Van Campenhout ve arkadaşları Perthes hastalarında yaptıkları çalışmada, sintigrafik vaskülarizasyon yapısı ile Catterall ve Herring sınıflamaları arasında belirgin korelasyon saptamışlardır. ${ }^{[19]}$

\section{HASTANIN RADYASYONDAN KORUNMASI}

Pelvisin radyolojik incelenmesi sırasında hastanın üreme organlarının korunması gerekir. Bu koruma iki tipte olabilir: düz kontakt korumalar veya gölge korumalar. Düz kontakt korumalar hastanın yaşına uygun olacak şekilde kesilmiş değişik boyutta olan kurşun tabakalardır. Erkek hastalarda testislerin üzerine, kız hastalarda ise alt kısmı pubise gelecek şekilde üçgen koruma yerleştirilir. Gölge koruma ise $\mathrm{X}$-ışını tüpünün üzerine yerleştirilen radyoopak malzeme ile sağlanır.

En iyi radyasyondan korunma, gereksiz yere uygulanan radyografilerden kaçınmakla olur.

\section{KAYNAKLAR}

1. Boniforti FG, Fujii G, Angliss RD, Benson MK. The reliability of measurements of pelvic radiographs in infants. J Bone Joint Surg Br 1997;79(4):570-5.

2. Tönnis D. Congenital dysplasia and dislocation of the hip in children and adults. Berlin Heidelberg: Springer-Verlag; 1987.

3. Tönnis D. Normal values of the hip joint for the evaluation of X-rays in children and adults. Clin Orthop Relat Res 1976;(119):39-47.

4. BallF, Kommenda K. Sources of error in the roentgen evaluation of the hip in infancy. Ann Radiol (Paris)1968;11(5):298-303.

5. Klein A, Joplin RJ, Reidy JA, Hanelin J. Slipped capital femoral epiphysis; early diagnosis and treatment facilitated by normal roentgenograms. J Bone Joint Surg Am 1952;34-A(1):233-9.
6. Hilgenreiner $\mathrm{H}$. Zur Frühdiagnose und Frühbehandlung der angeborenen Hüftgelenkverrenkung. Med Klin 1925;21:1385$8,1425-9$.

7. Yamamuro $\mathrm{T}$, Chene $\mathrm{SH}$. A radiological study on the development of the hip joint in normal infants. J Jpn Orthop Ass 1975;49:421-39.

8. Smith WS, Badgley CE, Orwig JB, Harper JM. Correlation of postreduction roentgenograms and thirty-one-year followup in congenital dislocation of the hip. J Bone Joint Surg Am 1968;50(6):1081-98.

9. Wiberg G. Studies on the dysplastic acetabulum and congenital subluxation of the hip joint: with special reference to the complication of osteoarthritis. Acta Chir Scand Suppl 1939;58:7-135.

10. Hefti F, Brunner R, Freuler F, Hasler CC, Jundt G. Pediatric Orthopedics in Practice. Berlin Heidelberg: Springer Verlag; 2007.

11. Lequesne $M$, de Seze. False profile of the pelvis. A new radiographic incidence for the study of the hip. Its use in dysplasias and different coxopathies. Rev Rhum Mal Osteoartic 1961;28:643-52.

12. Chan R, Schlechter J, Nguyen S, Lalonde F, Weinert C. Carbon dioxide gas arthrography for the evaluation of pediatric hip conditions: what is the risk and reliability? J Pediatr Orthop 2014;34(4):411-4. CrossRef

13. Laredo FJ. Legg-Perthes-Calvé disease: arthrographic classification. Rev Bras Orthop 1992;27:7-10.

14. Futami T, Suzuki S, Seto $Y$, Kashiwagi N. Sequential magnetic resonance imaging in slipped upper femoral epiphysis: assessment of preslip in the contralateral hip. J Pediatr Orthop B 2001;10(4):293-303.

15. Baunin C, Sanmartin-Viron D, Accadbled F, Sans N, Vial J, Labarre D, Domenech C, Sales de Gauzy J. Prognosis value of early diffusion MRI in Legg Perthes Calvé disease. Orthop Traumatol Surg Res 2014;100(3):317-21. CrossRef

16. Sebag G, Ducou Le Pointe H, Klein I, Maiza D, Mazda K, Bensahel $H$, Hassan $M$. Dynamic gadolinium-enhanced subtraction MR imaging--a simple technique for early diagnosis of Legg-Perthes-Calvé disease: preliminary results. Pediatr Radiol 1997;27(3):216-20.

17. Kashiwagi N, Suzuki S, Kasahara Y, Seto Y. Prediction of reduction in developmental dysplasia of the hip by magnetic resonance imaging. J Pediatr Orthop 1996;16(2):254-8.

18. Conway JJ. A scintigraphic classification of Legg-PerthesCalvé disease. Semin Nucl Med 1993;23(4):274-95.

19. Van Campenhout A, Moens P, Fabry G. Serial bone scintigraphy in Legg-Calvé-Perthes disease: correlation with the Catterall and Herring classification. J Pediatr Orthop B 2006;15(1):6-10. 